\title{
OPEN The role of folded fibular flap in patients' reconstruction of mandibular defects: a retrospective clinical study
}

\author{
Ning Gao, Kun Fu, Jinghua Cai, Hao Chen \& Wei He
}

This study has analyzed 41 patients with mandibular ameloblastoma who underwent a partial mandibulectomy and reconstruction by folding the free fibular flap. In the preoperative and postoperative ( 6 months and 24 months after surgery), the Quality of Life (QOL) of these patients was assessed by using the University of Washington Quality of Life Questionnaire (UW-QOL) and the medical outcome study short form-36 (SF-36) questionnaires. SPSS 20.0 statistical software was used to conduct statistical analysis on the base data of the two groups of patients. Independent sample $t$ test was conducted for sf-36 and UW-QOL scores at two time points in each group. The SF-36 survey showed that body pain $(54.54 \pm 8.10)$, general health $(55.27 \pm 7.54)$, and health changes $(58.29 \pm 9.60)$ decreased significantly at 6 months after surgery, but the mean score at 24 months after surgery all exceeded the preoperational level. At 24 months after the surgery, the vitality $(80.41 \pm 3.74)$, social function $(81.61 \pm 4.07)$, emotional role $(82.39 \pm 4.07)$, psychological health $(81.66 \pm 4.37)$ and total score $(704.00 \pm 31.53)$ all returned to the preoperative level, which was statistically significant compared with 6 months after surgery. However, there was no significant difference compared with the preoperative level. The UW-OOL survey showed that chewing $(56.68 \pm 7.23)$, speech $(54.54 \pm 7.7)$ and taste $(62.29 \pm 10.15)$ have significantly changed at 6 months after the surgery, and the difference was statistically significant at 24 months after surgery. Saliva generation decreased slightly $(80.76 \pm 3.35)$ at 6 months after surgery, but quickly returned to the preoperative level $(81.59 \pm 4.06)$. The total score of the patients almost recovered to the preoperative level at 24 months after surgery. The folded the fibular flap can not only repair the defects of soft tissue and bone tissue, but also restore the height of the alveolar ridge to, avoid the imbalance of crown and root ratio after implantation and reduce the occurrence of peri-implant inflammation, so that a true functional reconstruction can be realized.

Since 1989 when Hidalgo first reported the success of using the free fibular flap to repair mandibular defects, the clinical application of this surgical technique to repair damage associated with tumor removal has seen further improvement ${ }^{1}$. With the constant improvement of the microsurgical technique ${ }^{2}$, as well as 3D printing ${ }^{3}$, the upgrade of free fibular flap surgical technique offers increasingly extensive applications in the repair of mandibular defects 4 . Ameloblastoma is a common cause of mandibular defects. The free fibula combined with dental implant technology for functional reconstruction of the mandible can effectively restore the patient's facial shape and occlusal relationship. However, the biggest disadvantage, the height of the reconstructed mandible cannot meet the needs of implant repair ${ }^{5}$. The mucosal scar on the surface of the single fibular is thick ${ }^{6}$, which not only increases the difficulty of imprinting ${ }^{7}$, but also easily produces peri-implant inflammation ${ }^{8}$. The folded fibular flap perfectly restores the height of the alveolar ridge, avoiding the imbalance of the coronal root ratio in implant repair.

With the transformation of the biomedical model into the bio-psycho-social medical model, the criteria for evaluating the effectiveness of tumor treatments, are no longer restricted purely to survival rate and biological indicators such as organ function reconstruction ${ }^{9}$, but now also encompass improvements made to the patients' $\mathrm{QOL}^{10}$. In this study, The UW-QOL and the SF-36 questionnaires were used to evaluate and analyze the QOL of patients with tumor removal related tissue defects, repaired with the folded fibular flap technique. This study 


\begin{tabular}{|l|l|}
\hline Variables & \multicolumn{2}{l|}{ Cases n (\%) } \\
\hline Age (years) & $29(70.73)$ \\
\hline$<50$ & $12(29.27)$ \\
\hline 50 and over & $26(63.41)$ \\
\hline Sex & $15(36.59)$ \\
\hline Male & \multicolumn{2}{|l|}{} \\
\hline Female & $19(46.34)$ \\
\hline Primary sites of tumor & $12(29.27)$ \\
\hline Body & $10(24.39)$ \\
\hline Body, angle & \multicolumn{2}{|l}{} \\
\hline Body, angle, ramus & $32(78.05)$ \\
\hline Clinical type & $9(21.95)$ \\
\hline Solid & $14(34.15)$ \\
\hline Unicystic & $27(65.85)$ \\
\hline Radiographic appearance & $10(24.39)$ \\
\hline Unilocular & $28(68.29)$ \\
\hline Multilocular & $3(7.32)$ \\
\hline Repair range & $37(90.24)$ \\
\hline Unilateral body & $4(9.76)$ \\
\hline Unilateral body and ramus & $9(21.95)$ \\
\hline Bilateral body & \multicolumn{2}{|l}{} \\
\hline Recipient artery & \\
\hline Facial artery & Superior thyroid artery \\
\hline Recipient vein & Unidentified branch of internal jugular vein \\
\hline External jugular vein & $32.05)$ \\
\hline
\end{tabular}

Table 1. Details of patients.

provides a basis for the formulation of a comprehensive treatment plan, the selection of surgical methods and repair methods, the postoperative functional rehabilitation and the possible psychological interventions resulting from the use of the fibular flap in the reconstruction of maxillofacial defects.

\section{Results}

All 41 cases undergoing this procedure survived. 39 patients healed in the first stage of healing, and two developed infection, which healed after antibiotic treatment and local dressing changes. The shaping time for the fibular was 43-90 $\mathrm{min}$, with an average of $(61 \pm 12) \mathrm{min}$, and the total operation time was 314-406 min, with an average of $(356 \pm 22) \mathrm{min}$. There were 40 cases of primary healing in the donor area and 1 case of scar healing after partial skin necrosis. Patients were able to return to their normal preoperative functional status at 6 weeks. The patients self-reported that there were no obvious abnormalities in the lower limb function compared with the preoperative level. Patients were questioned as to differences in sensation motor function etc. between the 2 limbs and preop status and this was also negative. There was no tenderness in the temporomandibular joint area and the degree of opening was $3.1-3.9 \mathrm{~cm}$ in 39 patients. Implants were implanted at 6-9 months after surgery, and the porcelain crown was repaired 3-4 months later. The implant bone was well combined, the occlusal relationship was restored, and the functions of speech, chewing and swallowing were returned to normal. All patients recovered the natural curvature, height and occlusal relationship of the defect area of the mandible, and no obvious abnormalities were found in the operative area. There were no obvious complications in the donor area, the lower limbs could bear weight, walking was not affected, and the donor area of the legs had no obvious dysfunction. There was no obvious peri-implantitis at the follow-up visit. All 41 patients completed the survey, and the completion rate was $100 \%$. The general situation is shown in Table 1.

SF-36 survey results. The specific score of SF-36 is shown in Table 2. The Physical role decreased significantly after the surgery. Although there was a significant improvement in the 24 months after the surgery compared with the first 6 months after the surgery $(\mathrm{t}=-5.134, \mathrm{p}=0.000)$, it still could not return to the preoperative level $(\mathrm{t}=11.685, \mathrm{p}=0.003)$. Body pain (54.54 \pm 8.10$)$, general health $(55.27 \pm 7.54)$, and health changes $(58.29 \pm 9.60)$ decreased significantly at 6 months after surgery, but the mean score at 24 months after surgery all exceeded that before surgery.

At 24 months after the operation, vitality $(80.41 \pm 3.74)$, social function $(81.61 \pm 4.07)$, emotional role $(82.39 \pm 4.07)$, psychological health $(81.66 \pm 4.37)$ and total score $(704.00 \pm 31.53)$ all returned to the preoperative 


\begin{tabular}{|l|l|l|l|l|l|l|}
\hline \multirow{2}{*}{ Domains } & \multicolumn{3}{|l|}{ Mean \pm standard deviation } & \multicolumn{3}{l|}{ Comparison of t value (P value) at different time } \\
\cline { 2 - 7 } & Preoperative & $\mathbf{6}$ months & $\mathbf{2 4}$ months & $\begin{array}{l}\text { Preoperative and 6 } \\
\text { months }\end{array}$ & $\begin{array}{l}\text { Preoperative and } \\
\mathbf{2 4} \text { months }\end{array}$ & $\begin{array}{l}\text { 6 months and 24 } \\
\text { months }\end{array}$ \\
\hline $\begin{array}{l}\text { Physiological func- } \\
\text { tion }\end{array}$ & $67.88 \pm 5.77$ & $48.34 \pm 12.05$ & $69.54 \pm 7.29$ & $9.365(0.000)$ & $-9.635(0.002)$ & $-1.142(0.282)$ \\
\hline Physical role & $80.05 \pm 9.41$ & $44.90 \pm 16.98$ & $59.41 \pm 6.27$ & $11.594(0.001)$ & $11.685(0.003)$ & $-5.134(0.000)$ \\
\hline Body pain & $72.00 \pm 10.70$ & $54.54 \pm 8.10$ & $82.44 \pm 12.90$ & $8.333(0.001)$ & $-3.989(0.000)$ & $-11.727(0.000)$ \\
\hline General health & $72.85 .4 \pm 9.50$ & $55.27 \pm 7.54$ & $83.17 \pm 12.07$ & $9.285(0.018)$ & $-4.300(0.053)$ & $-12.554(0.000)$ \\
\hline Vitality & $82.44 \pm 5.20$ & $77.78 \pm 6.60$ & $80.41 \pm 3.74$ & $3.552(0.366)$ & $2.024(0.163)$ & $-2.224(0.036)$ \\
\hline Social function & $84.00 \pm 5.19$ & $76.07 \pm 7.40$ & $81.61 \pm 4.07$ & $5.616(0.066)$ & $2.321(0.107)$ & $-4.197(0.002)$ \\
\hline Emotional role & $82.78 \pm 4.23$ & $74.83 \pm 6.66$ & $82.39 \pm 4.07$ & $6.457(0.006)$ & $0.426(0.998)$ & $-6.204(0.005)$ \\
\hline Psychological health & $80.05 \pm 4.01$ & $72.15 \pm 7.97$ & $81.66 \pm 4.37$ & $5.674(0.000)$ & $-1.738(0.415)$ & $-6.701(0.000)$ \\
\hline Health change & $77.95 \pm 3.81$ & $58.29 \pm 9.60$ & $83.37 \pm 4.83$ & $12.188(0.000)$ & $-5.637(0.037)$ & $-14.939(0.002)$ \\
\hline Total & $700.00 \pm 32.10$ & $557.41 \pm 49.24$ & $704.00 \pm 31.53$ & $15.533(0.000)$ & $-0.569(0.893)$ & $-16.053(0.000)$ \\
\hline
\end{tabular}

Table 2. Means of scores of items and scales of SF-36 Questionnaire.

\begin{tabular}{|l|c|l|l|l|l|l|}
\hline \multirow{4}{*}{ Domains } & \multicolumn{3}{|l|}{ Mean \pm standard deviation } & \multicolumn{2}{l|}{ Comparison of t value (P value) at different time } \\
\cline { 2 - 7 } & Preoperative & $\mathbf{6}$ months & $\mathbf{2 4}$ months & $\begin{array}{l}\text { Preoperative and 6 } \\
\text { months }\end{array}$ & $\begin{array}{l}\text { Preoperative and 24 } \\
\text { months }\end{array}$ & $\begin{array}{l}\text { 6 months and 24 } \\
\text { months }\end{array}$ \\
\hline Swallowing & $64.17 \pm 3.47$ & $61.51 \pm 3.61$ & $64.78 \pm 3.39$ & $3.401(0.982)$ & $-0.804(0.791)$ & $-4.225(0.787)$ \\
\hline Speech & $63.76 \pm 2.91$ & $54.54 \pm 7.7$ & $63.9 \pm 2.9$ & $9.802(0.000)$ & $-0.223(0.596)$ & $-11.675(0.000)$ \\
\hline Taste & $81.92 \pm 4.33$ & $62.29 \pm 10.15$ & $74.66 \pm 9.83$ & $11.385(0.000)$ & $4.331(0.001)$ & $-5.601(0.693)$ \\
\hline Saliva & $81.46 \pm 6.51$ & $80.76 \pm 3.35$ & $81.59 \pm 4.06$ & $0.619(0.004)$ & $-0.102(0.056)$ & $-1.009(0.114)$ \\
\hline Total & $359.68 \pm 10.39$ & $315.78 \pm 20.25$ & $354.12 \pm 11.75$ & $12.354(0.000)$ & $0.402(2.271)$ & $-10.489(0.001)$ \\
\hline
\end{tabular}

Table 3. Means of scores of items and scales of UW-QOL questionnaire.

level, which was statistically significant compared with the 6 months after the operation, but there was no significant difference compared with the preoperative level.

UW-QOL survey results. The specific score of UW-QOL is shown in Table 3. The items with significant changes after 6 months were chewing (56.68 \pm 7.23$)$, speech (54.54 \pm 7.7$)$ and taste (62.29 \pm 10.15$)$, which have significantly improved at 24 months after the surgery and the difference was statistically significant. Saliva generation decreased slightly $(80.76 \pm 3.35)$ at 6 months after surgery, but quickly returned to the preoperative level $(81.59 \pm 4.06)$.

There was no significant change in the swallowing function after the surgery, and the total score of the patients almost recovered to the preoperative level at 24 months after the surgery $(t=2.271, p=0.402)$.

\section{Discussion}

The mandibular defects directly affect the facial features, masticatory and articulation functions of the patient ${ }^{11}$. This damage also restricts the daily life and social activities of the patients to different degrees, and indirectly affects the psychological state and social activities of the patients ${ }^{12}$. Traditional indicators for the evaluation of oral diseases do not consider the impact of diseases on the quality of life of patients. With the change of medical model, it has become a goal that surgeons pursue to ensure patients receive better QOL while prolonging the survival of tumor patients through medical intervention ${ }^{13}$.

With the constant improvement of the microsurgical technique, as well as 3D printing, the upgrade of free fibular flap surgical technique offers increasingly extensive applications in the repair of the mandibular defects ${ }^{14}$. It can repair not only bone tissue defects, but also soft tissue defects. When looking to repair the upper and lower jaw and adjacent tissue defects it is the tissue flap of choice. However, the biggest disadvantage when using the fibular flap is that the height is only $1.3-1.5 \mathrm{~cm}$. Therefore, the height of the reconstructed mandible cannot meet the needs of implant repair. In addition, the mucosal scar on the surface of the single fibular is thick, which not only increases the difficulty of imprinting ${ }^{15}$, but also easily produces peri-implant inflammation (Fig. 1). Alternatively, the folded fibular flap perfectly restores the height of the alveolar ridge, avoiding the imbalance of the coronal root ratio in implant repair ${ }^{16}$. The thin crest mucosa reduces the incidence of peri-implant inflammation, which greatly improved the sample patient groups chewing function, language expression, and further increased the patient's confidence. All flaps of the selected cases in this group survived. This included the 2 patients presenting with flap crisis at 12-24 h after the operation which resulted in blocked venous reflux from poor drainage. The flap remained completely viable following efforts to improve drainage, which involved the removal of blood clots at the bottom of the mouth and microthrombus at the anastomosis ${ }^{17}$. 


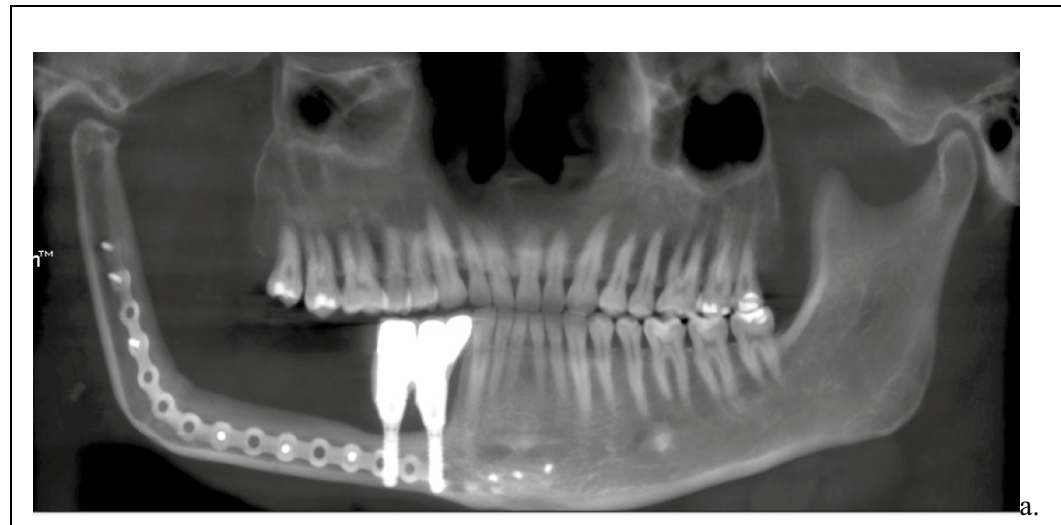

(a) Imbalance of the coronal root ratio.

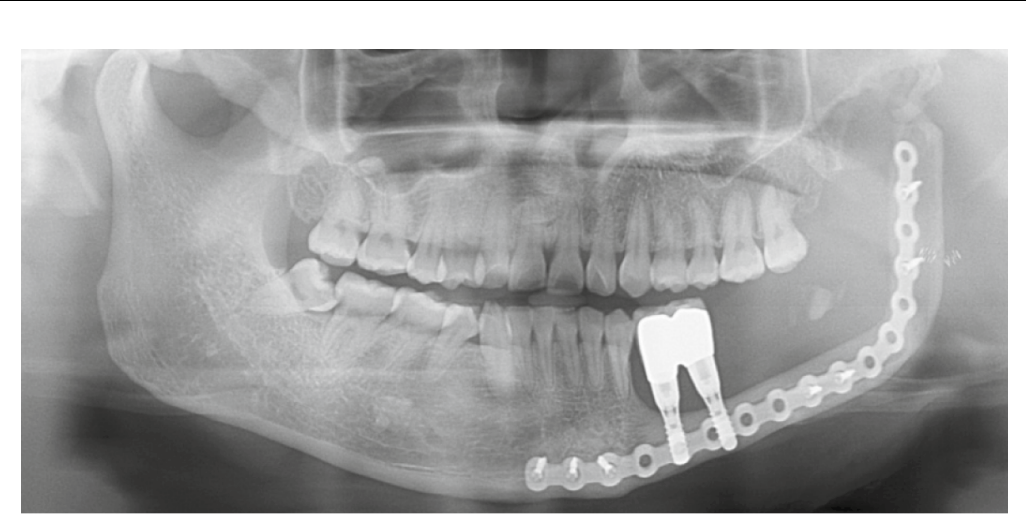

(b) The molar occlusal relationship could not be restored because of the difficulty of implantation.

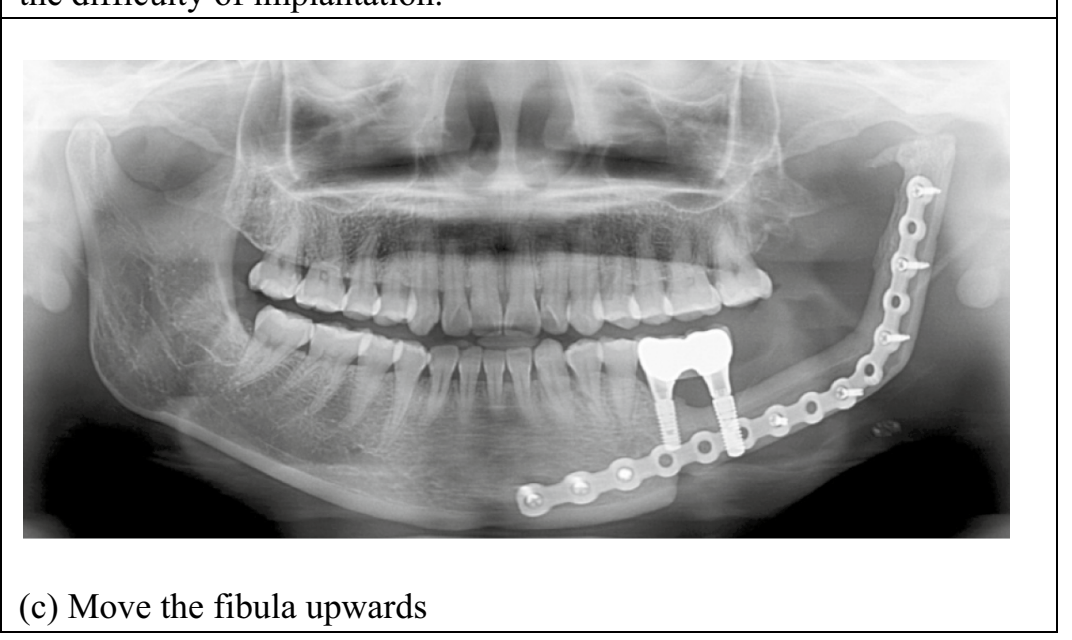

Figure 1. (a) The height of the reconstructed mandible cannot meet the needs of implant repair. (b) The mucosal scar on the surface of the single fibular is thick, which not only increases the difficulty of implanting and imprinting, but also easily produces peri-implant inflammation. (c) We can move the fibula upwards, but this may result in maxillofacial asymmetry.

After fibular transplantation, more than $90 \%$ of the follow-up patients reported that the discomfort of lower limb pain, weakness, numbness and other discomfort gradually disappeared after 6 months, and the feeling and function of lower limb movement were basically normal, without affecting daily activities, which indicated that the flap resection of the donor area had almost no effect on the mobility of the patients.

The SF-36 results show that: (1) all functions of the patients recovered after the surgery, but the body still could not return to the preoperative level at 24 months after the surgery, the patients still felt slight discomfort in the lower limbs, itching in the scar, and even some patients still could not fully accept the fact that the fibular flap 
was placed in the maxillofacial region. (2) body pain, general health and health changes decreased significantly after the surgery, which was related to the recovery of the lower limbs of the patients. With the further exercise of function and the restoration of implant teeth, the average score at 24 months after the surgery was higher than the preoperational level, and the difference was statistically significant. (3) physiological function, vitality, social function, emotional role, mental health and the total score decreased significantly at 6 months after the operation, which was significantly related to the surgical trauma and the self-discomfort of the patients, but recovered to the preoperative level at 24 months after the operation.

UW-QOL results show that: (1) with the passage of time, the oropharyngeal function of the patients after the operation was significantly improved, especially after the implant was used to repair the dentition defect, the chewing and language of the patients were substantially changed. (2) some patients suffered from damage to the lingual nerve during the operation, postoperative tongue numbness and a decline in taste. This generally recovered 3 months following the operation. (3) since the submandibular gland of the affected side will be routinely removed during the operation, there will be a temporary decrease in the amount of saliva produced after the operation, but with the compensation of other glands, the patient's symptoms decreased significantly. Results from the survey indicate that the impact on swallowing as a result of this surgery is not significantly adverse.

Emotional factors are the most influential issues for cancer patients ${ }^{12}$. We found that while the patient recovered in terms of physiological function, social function and family status, the emotional status could not return to the normal level at 6 months after the surgery ${ }^{18}$. The low scores of patients in mental health are largely related to the psychological reality of patients' inability to accept jaw resection and their inability to adapt to changes in basic life functions such as speech and eating after surgery ${ }^{19}$. Patients are always worried about the recurrence of the tumor and the uncertainty of the future ${ }^{20}$, so they often experience symptoms such as irritability, fatigue, insomnia, pain, diarrhea and constipation ${ }^{21-24}$. This indicates that the emotional damage caused by the tumor to patients is more serious and long-lasting ${ }^{25}$. Patients think they are sicker than others and that their health is deteriorating ${ }^{26}$. Therefore, psychological and emotional rehabilitation treatment for patients is very important ${ }^{27}$. The psychological problems of cancer patients have aroused the attention of clinicians. While treating the patients' diseases, the patients should be taught about the disease knowledge before the operation to alleviate their fear and anxiety about the unknown. After the operation, the discomfort of the oral, maxillofacial and lower limbs should be diagnosed and treated in a timely manner, and the patients should be encouraged to actively participate in social activities. At the same time, the survey shows that the encouragement and support of family members play a vital role in the physical and mental health of patients, and the love from family members makes it easier for patients to recover from the trauma of the disease. Therefore, the patient's psychological discomfort and social disorder require not only the joint efforts of doctors and patients, but also the care and support of family members.

The surface of a single layer fibula is covered with thick scars and mucous membranes, which is prone to peri-implant inflammation. It is advised that peri-implantitis and mucositis after fibula repair were identified in $14.8 \%$ and $20.3 \%$ of surviving implants, respectively, at the 5 - and 10 -year follow-up ${ }^{28}$. The study also suggests that skin or connective tissue grafts seem to offer an aid to manage this problem. We have found in the clinic that the incidence of peri-implant inflammation after folding the fibula is relatively low. This is because the mucosa on the surface is thin, which facilitates the smooth neck of the implant to penetrate the gums and facilitates the self-cleaning of the implant neck. The 12-month clinical trials have shown that there is no significant difference between the restoration supported by a single short implant and the long implant ${ }^{29,30}$. Although the three-year clinical trial of 2018 supported the view mentioned above ${ }^{31}$, the seven-year clinical study of 2021 concluded that the survival rate of short implants was significantly lower than that of conventional implants ( $87 \%$ vs. $100 \%)^{32}$. At present, there is no relevant research on the restoration of multiple missing teeth on the fibula. Therefore, we also need to make more efforts in the clinic to study whether the use of crown-to-root ratio in a single-layer fibula is not different from that of a folded fibula.

It is suggested that the folded fibula is the best repair and reconstruction plan for the defect of the middle part of the mandible, and it provides a good foundation for implant restoration ${ }^{33}$. Compared with the conventional one-strut fibula transplant, the "double-barrel" graft achieved more bone height and appreciably reduced the vertical distance to the occlusal plane. This technique creates better conditions for prosthetic rehabilitation. The folded fibula and iliac bone graft can better reconstruct the vertical height of fibula than vertical traction ${ }^{34,35}$.

The implant restoration after fibular transplantation is still in the exploratory stage. Therefore, the sample size is small, and the follow-up time is not long enough. In the subsequent research, we will also focus on the problems caused by peri-implant inflammation and crown-to-root ratio imbalance.

\section{Materials and methods}

Patients. Forty-one cases with mandibular ameloblastoma underwent partial mandibulectomy and repair utilizing the fibular flap technique. This was performed in the oral and maxillofacial surgery department of the first affiliated hospital of Zhengzhou university from October 2012 to July 2017. There were 26 males and 15 females. The age ranged from 18 to 58 years old, with an average of 34.8 years old. The inclusion criteria 
were as follows: (1) preoperative design was carried out using 3D printing technology and digital technology, intraoperative resection of the diseased mandible was performed, and the fibular flap technique was used for reconstruction and repair at the same time. (2) No serious complications after the operation. (3) No recurrence of the primary disease. (4) Implant repair was performed at 6-9 months after surgery. The observation period was longer than 24 months.

Sequential treatment steps. The CT data of the patient's maxillofacial region and legs which has been obtained before the surgery has been imported into Mimics Research 20.0 software (Belgium Materialise company, https://www.materialise.com/) to complete the 3D reconstruction of the jaw. The scope of resection was clarified when the extent affected by tumor was determined, and then the digital technology was employed to simulate partial resection of the mandible. The mandible date of the healthy side was copied to the affected side by mirroring method and its position was adjusted appropriately. Then after importing the patient's fibula data, the fibula was cut and shaped according to the best shape of the defect area to be restored. Finally, a 3D head mold was printed, and the titanium plate was pre-bent on the head mold. The operation was carried out in two groups at the same time: one group received a partial mandibulectomy according to the lesion range, retaining the articular disc. The condyle was retained depending on the situation with work on the arteriovenous system carried out in the receiving area. In the other group, the Henry approach was adopted in the posterolateral part of the calf, and the fibular flap was made conventionally. Depending on the defect range, the skin island and fibular length of the free fibular composite flap and the required muscles were designed according to the preoperative digital design scheme. The fibular flap was fixed with a Swiss sinins AO 2.0 prefabricated titanium plate before the pedicle fracture. The branches of the peroneal artery and the external carotid artery were manually sutured with 8-0 Prolene line, and then the peroneal vein was anastomosed with the internal (external) jugular vein with a microvascular anastomosis device to reconstruct blood circulation. The Straumann implant system was used to implant 4.1 standard neck implants at the level of soft tissue through fixed points and stage by stage holes. The length was $10-14 \mathrm{~mm}$ and the smooth neck was located at the top of the alveolar crest. Porcelain crown restoration was carried out 3 to 4 months after implantation (Fig. 2).

Questionnaire and collection. SF-36 and UW-QOL are available in Chinese and have been validated for a Chinese population.

(1) SF-36 is a widely used QOL measurement tool to assess the impact of overall health status on QOL. This questionnaire has been used by scholars to evaluate the QOL of cancer patients in China. It mainly includes 9 aspects of physiological function, body pain, physical role, general health, vitality, emotional role, social function, health change and psychological health. The maximum score of each item is 100 . The higher the score is, the better the status is.

(2) UW-QOL is a self-administered questionnaire that designed for patients with head and neck cancer. Internationally it is one of the most commonly used head and neck cancers QOL questionnaires in use. It includes pain, appearance, activity, entertainment, swallowing, chewing, language, mouth opening, taste, saliva, mood, anxiety, and overall well-being. The domains are scored on a scale ranging from 0 (worst) to 100 (best). Chewing, swallowing, speech, taste and saliva can be used to assess the patient's oral function.

Assessment methods. SF-36 and UW-QOL questionnaires were used in the survey, and a combination of doctor's examinations and questionnaire were adopted in the methodology. Before the operation, the survey (utilizing both types of assessment questionnaires were explained to the patients in full detail. The patients were then instructed to fill in the first questionnaire pre operation, with the second and third surveys to be filled in at 6- and 24-month post operation, respectively. A scoring manual provided by the designer of the questionnaire was used for scoring patient symptoms.

Statistical analysis. SPS 20.0 statistical software was used to conduct statistical analysis on the base data of the two groups of patients. Independent sample $t$ test was conducted for sf-36 and UW-QOL scores at two time points in each group.

Ethical approval. This study was conducted under the regulations and guidelines in accordance with institutional research ethics board at The First Affiliated Hospital of Zhengzhou University, Zhengzhou, China (2012-KY-230) and with the 1964 Helsinki declaration and its later amendments or comparable ethical standards. All methods and experimental protocols were reviewed and approved by the research ethics board prior to initiating the study. Informed consent for participation and publication of the images has been obtained from all the participants. 


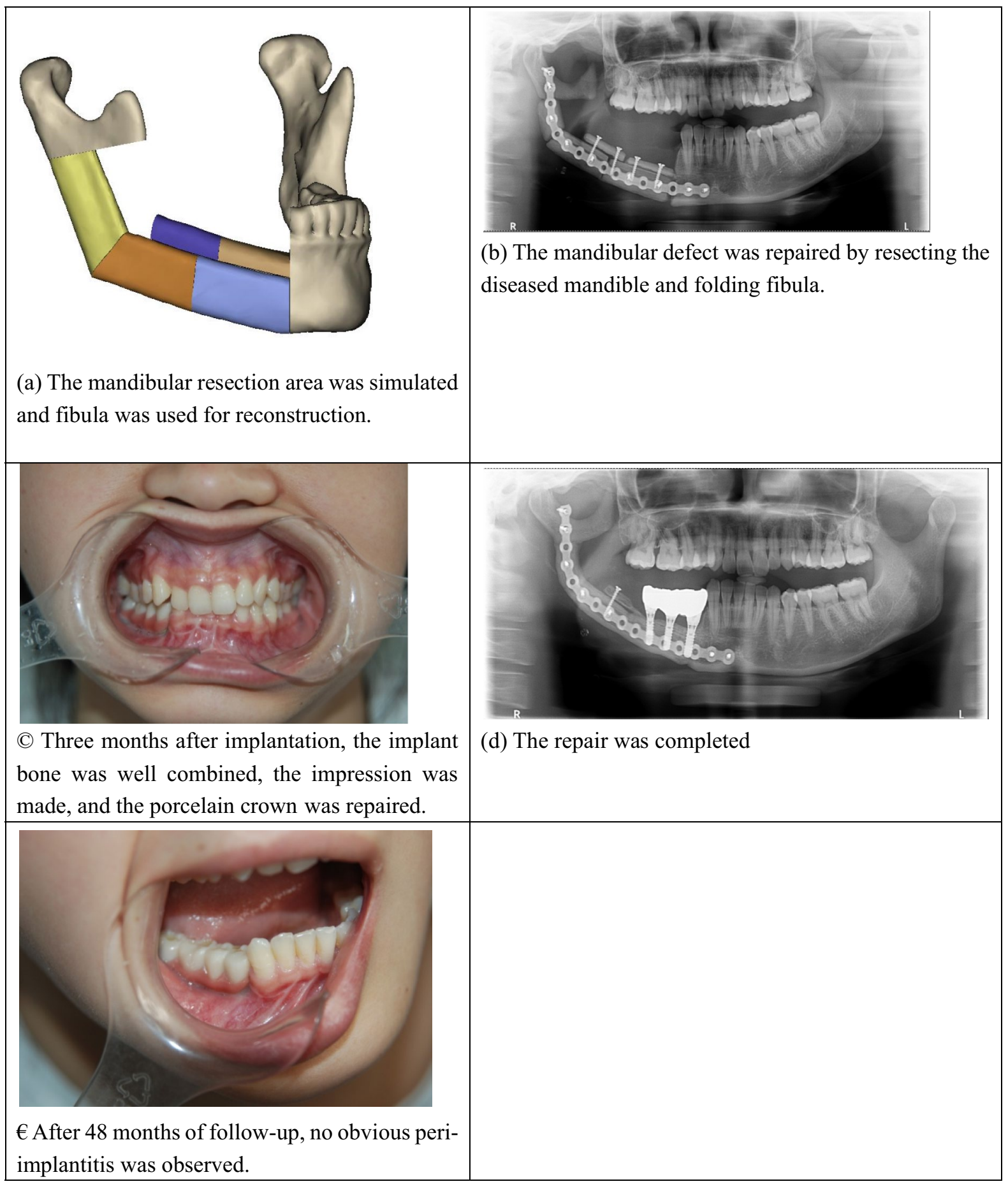

Figure 2. (a) The mandibular resection area was simulated and fibula was used for reconstruction. (b) The mandibular defect was repaired by resecting the diseased mandible and folding fibula. (c) Three months after implantation, the implant bone was well combined, the impression was made, and the porcelain crown was repaired. (d) The repair was completed. (e) After 48 months of follow-up, no obvious peri-implantitis was observed.

Received: 19 February 2021; Accepted: 29 November 2021

Published online: 13 December 2021

\section{References}

1. Yao, Y. et al. Regeneration of the neocondyle after free fibularr flap reconstruction of the mandibular condyle. J. Oral. Maxil. Surg. 78, 479-487 (2020).

2. Seruya, M., Fisher, M. \& Rodriguez, E. D. Computer-assisted versus conventional free fibularr flap technique for craniofacial reconstruction: An outcomes comparison. Plast. Reconstr. Surg. 132, 1219-1228 (2013). 
3. Davey, M., McInerney, N. M., Barry, T., Hussey, A. \& Potter, S. Virtual surgical planning computer-aided design-guided osteocutaneous fibular free flap for craniofacial reconstruction: A novel surgical approach. Cureus 11, e6256 (2019).

4. Qu, X. et al. Occlusion guided double-barreled fibular osteoseptocutaneous free flap for refined mandibular reconstruction aided by virtual surgical planning. J. Craniofac. Surg. 28, 1472-1476 (2017).

5. Shokri, T., Stahl, L. E., Kanekar, S. G. \& Goyal, N. Osseous changes over time in free fibular flap reconstruction. Laryngoscope 129, 1113-1116 (2019).

6. Pauchet, D., Pigot, J. L., Chabolle, F. \& Bach, C. A. Prefabricated fibula free flap with dental implants for mandibular reconstruction. Eur. Ann. Otorhinolaryngol. Head Neck Dis. 135, 279-282 (2018).

7. Barber, B. R. et al. Bone-impacted fibular free flap: Long-term dental implant success and complications compared to traditional fibular free flap tissue transfer. Head Neck. 38, E1783-E1787 (2016).

8. Chang, Y. M. et al. Outcome of osseointegrated dental implants in double-barrel and vertically distracted fibula osteoseptocutaneous free flaps for segmental mandibular defect reconstruction. Plast. Reconstr. Surg. 134, 1033-1043 (2014).

9. Vu, D. D. \& Schmidt, B. L. Quality of life evaluation for patients receiving vascularized versus nonvascularized bone graft reconstruction of segmental mandibular defects. J. Oral. Maxillofac. Surg. 66, 1856-1863 (2008).

10. Löfstrand, J. et al. Quality of life after free fibula flap reconstruction of segmental mandibular defects. J. Reconstr. Microsurg. 34, 108-120 (2018).

11. Barla, M. et al. Free vascularised fibular flap harvesting in children: An analysis of donor-site morbidity. Orthop. Traumatol. Surg. Res. 103, 1109-1113 (2017).

12. Halim, A. S. et al. Long-term outcome of free fibular osteocutaneous flap and massive allograft in the reconstruction of long bone defect. J. Plast. Reconstr. Aesthet. Surg. 68, 1755-1762 (2015).

13. Laraway, D. C. \& Rogers, S. N. A structured review of journal articles reporting outcomes using the University of Washington Quality of Life Scale. Br. J. Oral Maxillofac. Surg. 50, 122-131 (2012).

14. Salvatore, B. et al. Computer-assisted surgery for reconstruction of complex mandibular defects using osteomyocutaneous microvascular fibularr free flaps: Use of a skin paddle-outlining guide for soft-tissue reconstruction A technical report. J. Cranio Maxill. Surg. 47, 293-299 (2019).

15. Patel, A., Harrison, P., Cheng, A., Bray, B. \& Bell, R. B. Fibular reconstruction of the maxilla and mandible with immediate implantsupported prosthetic rehabilitation: Jaw in a day. Oral Maxillofac. Surg. Clin. N. Am. 31, 369-386 (2019).

16. Chana, J. S. et al. Segmental mandibulectomy and immediate free fibular osteoseptocutaneous flap reconstruction with endosteal implants: An ideal treatment method for mandibular ameloblastoma. Plast. Reconstr. Surg. 113, 80-87 (2004).

17. Wu, H. X. et al. Identification of independent risk factors for complications: A retrospective analysis of 163 fibularr free flaps for mandibulofacial reconstruction. J. Oral Maxilofac. Surg. 76, 1571-1577 (2018).

18. Murphy, B. A., Ridner, S., Wells, N. \& Dietrich, M. Quality of life research in head and neck cancer: A review of the current state of the science. Crit. Rev. Oncol. Hematol. 62, 251-267 (2007).

19. Cousins, N., MacAulay, F., Lang, H., MacGillivray, S. \& Wells, M. A systematic review of interventions for eating and drinking problems following treatment for head and neck cancer suggests a need to look beyond swallowing and trismus. Oral Oncol. 49, $387-400$ (2013).

20. Mücke, T. et al. Quality of life after different oncologic interventions in head and neck cancer patients. J. Craniomaxillofac. Surg. 43, 1895-1898 (2015).

21. Li, H. et al. Mandibular lingual release versus mandibular lip-split approach for expanded resection of middlelate tongue cancer: A case-control study. J. Craniomaxillofac. Surg. 43, 1054-1058 (2015).

22. Wang, Y. L., Peng, X. \& Luo, Y. Quality-of-life outcomes of the patients with tongue cancer following reconstruction with free forearm flap. Chin. J. Stomatol. 46, 27-30 (2011).

23. Zhang, X. et al. Free fibula flap: Assessment of quality of life of patients with head and neck cancer who have had defects reconstructed. J. Craniofac. Surg. 24, 2010-2013 (2013).

24. Baron, S. et al. Fibula free flap in the treatment of mandibular osteoradionecrosis. Eur. Ann. Otorhinolaryngol. Head Neck Dis. 133, 7-11 (2016).

25. Li, X., Zhu, K., Liu, F. \& Li, H. Assessment of quality of life in giant ameloblastoma adolescent patients who have had mandible defects reconstructed with a free fibula flap. World J. Surg. Oncol. 12, 201 (2014).

26. Jarefors, E. \& Hansson, T. Functional outcome in 17 patients whose mandibles were reconstructed with free fibular flaps. J. Plast. Surg. Hand Surg. 51, 178-181 (2017).

27. Petrovic, I. et al. A systematic review of validated tools assessing functional and aesthetic outcomes following fibula free flap reconstruction of the mandible. Head Neck 41, 248-255 (2019).

28. Pellegrino, G. et al. Long-term results of osseointegrated implant-based dental rehabilitation in oncology patients reconstructed with a fibula free flap. Clin. Implant Dent. Relat. Res. 20, 852-859 (2018).

29. Mendoza-Azpur, G. et al. Assessment of marginal peri-implant bone-level short-length implants compared with standard implants supporting single crowns in a controlled clinical trial: 12-month follow-up. Int. J. Periodont. Restor. 36, 791-795 (2016).

30. Nielsen, H. B., Schou, S., Bruun, N. H. \& Starch-Jensen, T. Single-crown restorations supported by short implants (6 mm) compared with standard-length implants $(13 \mathrm{~mm})$ in conjunction with maxillary sinus floor augmentation: A randomized, controlled clinical trial. Int. J. Implant Dent. 7, 1-12 (2021).

31. Hadzik, J. et al. The influence of the crown-implant ratio on the crestal bone level and implant secondary stability: 36-month clinical study. Biomed. Res. Int. 20, 20 (2018).

32. Hadzik, J. et al. Short $(6 \mathrm{~mm})$ and regular dental implants in the posterior maxilla-7-years follow-up study. J. Clin. Med. 10, 940 (2021).

33. Zavala, A., Al Deek, N. F., Chang, Y. M., Tsai, C. Y. \& Wei, F. C. Reconstruction of mandibular defects involving the central segment with fibula osteoseptocutaneous free flap following ameloblastoma resection: Patient-reported outcomes. J. Plast. Reconstr. Aesthet. Surg. 19, 3 (2021).

34. Bähr, W., Stoll, P. \& Wächter, R. Use of the "double barrel" free vascularized fibula in mandibular reconstruction. J. Oral Maxillofac. Surg. 56, 38-44 (1998).

35. Navarro Cuéllar, C. et al. Vertical ridge augmentation of fibula flap in mandibular reconstruction: A comparison between vertical distraction, double-barrel flap and iliac crest graft. J. Clin. Med. 10, 101 (2021).

\section{Author contributions}

N.G. was involved in the conception, design, and drafting the article. J.H.C., K.F. and H.C. were involved in the analysis and interpretation of data. W.H. was involved in revising the article critically for important intellectual content. All authors reviewed the manuscript.

\section{Competing interests}

The authors declare no competing interests. 


\section{Additional information}

Correspondence and requests for materials should be addressed to W.H.

Reprints and permissions information is available at www.nature.com/reprints.

Publisher's note Springer Nature remains neutral with regard to jurisdictional claims in published maps and institutional affiliations.

(c) (1) Open Access This article is licensed under a Creative Commons Attribution 4.0 International License, which permits use, sharing, adaptation, distribution and reproduction in any medium or format, as long as you give appropriate credit to the original author(s) and the source, provide a link to the Creative Commons licence, and indicate if changes were made. The images or other third party material in this article are included in the article's Creative Commons licence, unless indicated otherwise in a credit line to the material. If material is not included in the article's Creative Commons licence and your intended use is not permitted by statutory regulation or exceeds the permitted use, you will need to obtain permission directly from the copyright holder. To view a copy of this licence, visit http://creativecommons.org/licenses/by/4.0/.

(C) The Author(s) 2021 